\title{
ABOUT NARRATIVE: A STUDY ON THE USE OF NARRATIVES IN FASHION DESIGN
}

by

Laurence Fortin-Cote

Bachelor degree in Environmental Design, UQAM, 2017

An MRP presented to Ryerson University

in partial fulfillment of the requirements

for the degree of Master of Arts

in the program of Fashion (MA)

Toronto, Ontario, Canada, year of convocation, 2019

(C) Laurence Fortin-Cote, 2019 


\section{Author's declaration}

I hereby declare that I am the sole author of this MRP. This is a true copy of the MRP, including any required final revisions. I authorize Ryerson University to lend this MRP to other institutions or individuals for the purpose of scholarly research. I further authorize Ryerson University to reproduce this MRP by photocopying or by other means, in total or in part, at the request of other institutions or individuals for the purpose of scholarly research. I understand that my MRP may be made electronically available to the public. 


\begin{abstract}
This research examines the construction of narratives in fashion design. The intent is to explore how narratives emerge through this practice and how they impact the process of creation and making of fashion artefacts. It is constructed around a series of interviews with three fashion designers whose work reflects the importance of narratives as essential tools in their practice. All participants currently occupy a position in the fashion industry and have significant experiences that allowed them to share and express this area of their work. The analysis of these interviews forms the basis of a short documentary as well as the making of an art piece that are intended to encourage dialogue and deeper reflection about the ways in which narratives manifest themselves in the process of fashion design and how these they are later translated through the fashion industry. It examines how narratives can be used to generate meanings throughout the conception and production of garments and how these meanings can sensitize the consumers to the stories behind the clothes that they wear.
\end{abstract}




\section{Table of content}

Introduction

Review of literature

Theoretical framework....................................................................................

Methodological framework............................................................................

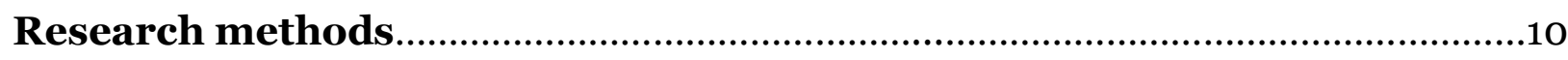

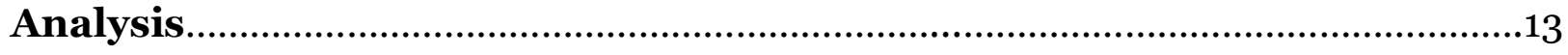

Michel Foucault's theory of authorship.................................................................13

Application of the concept of Author-Function......................................................14

Application of Foucault's concept of 'the work'.........................................................16

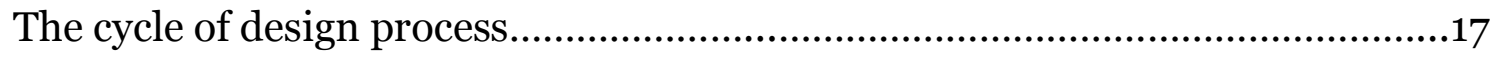

How narratives fit into the cycle of design process.................................................18

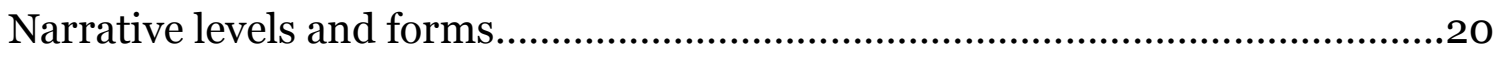

Applying Michel Foucault's concept of discursive practices.................................22

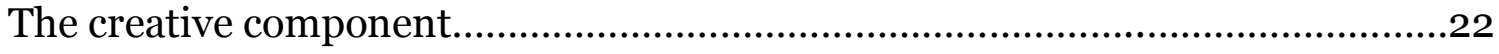

The art piece...........................................................................................22

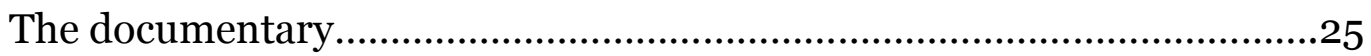

Creative practices as a source for the production of knowledge............................27

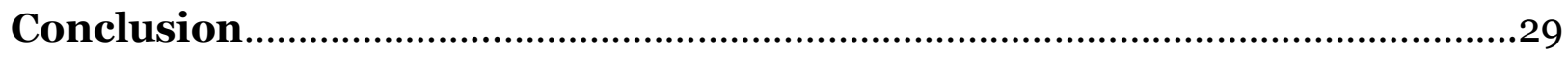

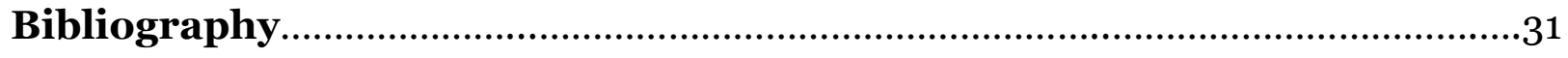




\section{Introduction}

In the second edition of his series of writings on critical thoughts called Transitions, Mark Currie says "narratives are as inescapable as language in general, or as cause and effect, as a mode of thinking and being."(6). Through this statement, Currie expresses that narratives are fundamental to the ways we communicate and process information and more importantly, as mentioned by Jerome S. Bruner in Acts of Meanings, narratives are essential tools in the communication of meanings (8). Both of these theorists, as well as many other researchers in this field, reinforce that the study of narratives can make it possible to access incredibly deep layers of information that would otherwise never be uncovered.

The study of narratives is a very well-established area of research, especially in the fields of cultural and literary studies which have been studied by theorists time and again throughout the twentieth and twenty-first century (Chakraborty 2959). Although most of the existing narrative theories apply to fields such as literature and anthropology, there has been a tendency in recent years towards diversifying the application of narrative theory, with a growing interest in art, design and other creative fields (Currie 5).

Despite the growing popularity of applying narrative research in the field of design, I believe that there remains a lack of diversity in terms of the disciplines that have been prioritized by theorists so far. In the introduction of her research Constructing a narrative of fashion practice as inquiry, Suzie R. Norris-Reeves explain that:

Whereas there is a significant literature on design theory written by theorists and not necessarily practitioners, and a considerable literature on fashion as object of 
sociological, historical, cultural, anthropological, semiotic, psychological, political, philosophical, economic study, there exists almost no serious study of fashion design practice from the perspective of the fashion designer (as practitioner). (3)

She then goes on to establish a thorough portrait of existing literature on the subject of design practice research, drawing the conclusion that prominent research in this field, such as Charles Burnette and Ken Friedman's approach to linear model of understanding how knowledge is communicated through intentions although are essential theories to consider, could benefit from an expansion in specific areas like fashion design (Norris-Reeves 55).

Studies such as Saikat Chakraborty's writings on using narratives in creativity research and Mark Currie's theory on postmodern narratives are indicative of a tendency towards adopting a rather broad approach to the implementation of narrative theory in design, and there is very little research that speaks directly to more specific areas of practice such as fashion design. In her essay Chakraborty mentions that: It is the lack of consensus in understanding creativity theoretically - We often tend to overlook the fact that creativity is both about the process as well as the outcome, and without truly embracing the process-perspective of understanding creativity, we cannot envision creativity as essential to human existence. Apparently, a deeper understanding of creativity needs to thrive in the modern business arena and researchers should contribute to both, the theory and the practice of understanding the creative process. (2960) 
Furthermore, in his book, Currie explains that the postmodern diversification of the field of narrative studies has made it harder for theorists to draw general conclusions which explains the need for more specific types of research.

If there is a contemporary narratological cliché it is exactly this claim that narratives are everywhere. So many recent studies begin by pointing out that narrative is not confined to literature. However, often it has been repeated, it is a key characteristic of the recent change in narratology: a massive expansion in the narratological remit, in the scope of objects for narratological analysis. (4)

These studies tend to address the subject of creativity as a whole and despite consisting of great introductions to the study of narratives in creative fields, such research is often harder to apply to specific contexts like fashion design. Suzie R. Norris-Reeves, who was one of the first to study fashion design from a practitioner perspective, tries to explain the lack of more specific applications of narrative theories in this field by indicating the nature of narratives as being often too difficult to express by practitioners as they are rooted in very personal and emotional spheres of their creative minds (51).

I have decided to embark on this journey that is my research on narratives because I have always cultivated a strong curiosity about how people make sense of what they create, and how they express and justify each decision that led to the final product. I believe that narratives are central and fundamental elements of design and that by paying attention to their subtleties it is possible to access a deeper understanding of the meanings behind artifacts produced by fashion designers. I am particularly interested in the many different forms under which this expression can manifest itself through the process of design and how essential it is to understand the meanings generated through this practice. Ultimately narratives can allow us to gain a better understanding of 
fashion design as a practice as well as how it is communicated to the public through the stories made by creative directors.

With this research, I hope to address the subjectivities associated with fashion design and to build on existing research about the use and significance of narratives. In her research Chakraborty quotes David M. Boje and his view on the subjective nature of creative processes in which he refers to the inevitable implications of "individual and social subjectivities" and their contribution in portraying creativity as harder to study or understand (Boje in Chakraborty 2967). Considering that little research has been conducted in this particular area of design, I wish to offer an updated perspective on the subject by investigating how narratives are constructed and manifested by designers, how they impact the process of creation and how they can act as generators of meaning.

To address these issues, I use Michel Foucault's theory of Author-function as well as Suzie R. Norris-Reeves' research Constructing a narrative of fashion practice as inquiry as the foundation of my theoretical framework and to ground the interpretation of my findings. Foucault's view on authorship allows me to identify what I called the cycle of design process and to establish how narratives fit the different stages of creation. I then use Mark Currie's point of view on postmodern narratives as an introduction to my methodological framework. After establishing the context of narrative in today's reality, I introduce a series of methods including Jan Blommaert's application of ethnopoetics, Jochen Kleres's approach of analysis of emotions in narratives and Saikat Chakraborty's method for addressing the subjectivities contained in creative practices. By applying those methods to my research, I then identify the four may levels of narratives and categorize them in order of importance based on my discussion with designers. I then go back to Foucault's theory, more specifically to his 
concept of discursive practices to explore the relationship of narratives with dialogues and how they will be expressed through the creative part of my research. Finally, I introduce the creative component of this research and its relation to my writings by applying Suzie R. Norris-Reeves's theory of creative practices as production of knowledge. I explain how making an art piece and expressing my findings in the form of a documentary help to give a visual voice to the stories collected through this research and share them to a larger audience.

\section{Review of literature}

Theoretical framework

Michel Foucault's theory of authorship forms the foundation for my research as it focuses on the relationship between an author and their work by establishing key concepts such as author-function, 'work' and 'discursive practices'. In his essay, What is an Author, Foucault first introduces his perspective on the phenomenon of individualization of authors and its effect on subjects such as authenticity and appropriation (115). According to Foucault, the analysis of a work should not be centered around its creator, rather it should focus on the unity that is generated by the multiple elements that form it, the author being just one of them (115). Varying from one work to another, and depending on the nature of the work, these elements are: the context in which the work has been created, its relation to other similar pieces and the reader or observer (Foucault 115) This point of view offers an interesting perspective to the subject of my research as it adds a level of interpretation of a designer's work, one that goes beyond the narratives generated through their intentions and personal signature. In fact, with his theory of authorship Foucault's offers a perspective that can 
be applied to the complexity of fashion narratives. His view decentres the idea of narrative in fashion from just the designer's intention and expression to include those who shape the narrative visually and textually, consumers of the designs, and the wearer's own resonance with, or extension of that narrative

Alongside Foucault's theory, Suzie R. Norris-Reeves' essay, Constructing a Narrative of Fashion Practice as Inquiry, is used. In this work, she proposes a framework to help validate the status of fashion designers as practitioners (169). She offers an updated perspective on Foucault's concept of 'the work' by elaborating a series of characteristics which centres the analysis of a designer's work around criteria that respect the designer's practice as meaningful and as a source for the production of knowledge. I use Foucault's global approach to the analysis of 'a work' and NorrisReeves methods to validate and build a more complex perspective of the meanings translated through the work of a designer, as well as the narratives it embodies and communicates, especially in relation to other works and to the context of fashion.

The second concept I use, which constitutes the core subject of Foucault's essay, focuses more specifically on the role of authors as creators which he defines as authorfunction (124). According to Foucault, the function of an author is 'to characterize the existence, circulation, and operation of certain discourses within a society.' (Foucault 124). Essentially, he purports that authors should not be seen as owners of ideas, but rather as actors in their creation and diffusion. This concept challenges the idea of agency associated with fashion designers as practitioners in their field since it distances them from a position of power in regard to their creations; in this context, fashion can be viewed as a discursive practice (131). This third element in Foucault's analysis of authorship explains how an author's responsibility goes beyond their own creative voice 
(131). For the purpose of my research, I use the concepts of author-function and discursive practices as guidelines in the analysis of my participants' perceptions of their practices and what it means to be a fashion designer in today's fashion context. I also use Norris-Reeves criteria for a meaningful practice in order to validate the status of a designer's practice in relation to other practitioners' work as well as other similar work that has been done in the past. These concepts help me dress a broader portrait of the creation and the implication of narratives in fashion design not only from the point of view of the practitioners, but also from my interpretation as a researcher.

Finally, I use Foucault's vision of authorship with Norris-Reeves' method to try to answer how fashion artefacts can generate meanings that go beyond what and who inspired their creation. Both of the theories presented by these authors help me frame my analysis of the ways in which fashion can generate meaning through the practice of design.

\section{Methodological framework}

Mark Currie's theory of postmodern narratives offers an approach to the analysis of narratives by positioning narrative studies in today's reality and by contextualizing the historical evolution and current state of this area of research (7). One of the main arguments that he defends in his writings is that postmodern narrative contexts of production ask for a diversification regarding the lens through which researchers look at them (Currie 6). I approached the analysis of my research by applying what he calls a 'less reductive reading' to the narratives I collected from participants (Currie 7). I also use what he defines as a 'cognitive approach' which essentially allows access deeper 
levels of thoughts and intentions by looking at how people express themselves in order to address the more sensitive subjects discussed during my interviews (Currie 18).

Since the subject of my research is oriented toward a personal aspect of design I apply a specific methodological framework that allows me to address the rather subjective nature of narratives as well as understand their level of complexity. Jan Blommaert suggests a method called ethnopoetics, first established by Hymes, which allows for specific types of application where 'different systems of meaning-making meet' (181). Essentially, this method is centred around the identification of patterns relating to the ways in which narratives are shared and communicated rather than solely focusing on the different elements contained in the stories being told (Blommaert 182). According to Blommaert, this way of interpreting narratives allows access to what he defines as 'poetic structures' which can be explained as specific ways people express narratives that cannot be accessed through the simple analysis of their content, but rather by focusing on more subtle elements such as emotion, gestures, omissions etcetera. I apply this interpretative method throughout my research to ensure a more complete analysis of the narratives collected during my interviews as well as to ensure that my findings are translated in the most accurate way possible.

In addition, I use Jochen Kleres's approach to the analysis of emotions in narratives to bring to light some of the more sensitive meanings that can generate a designer's desire to create and guide them in the process of making (187). As he argues in his essay Emotions and Narrative Analysis: A Methodological Approach, every form of narrative is structured by our emotions and can reveal deep levels of human experiences (Kleres 183). He states that, meanings are rooted in the emotional experiences expressed through narratives and it is only possible to get the full scope of 
their significance by analyzing and deconstructing those emotions (185). For this purpose, he elaborated a methodology of narrative emotion analysis that aims to access the 'linguistic manifestation of emotions - inextricably interwoven with the meaning dimension of texts.' (Kleres 188). With a more specific focus on the linguistic structure of speech, his method brings closer attention to the emotional side of narrative analysis, which applied alongside Blommaert's method, enriches the level of complexity of my findings. This combination of methods allows for treatment of participants' stories both accurately and sensitively with the translation of the emotional levels of their narratives through my research.

In order to analyze the elements of poetic structures obtained through Blommaert's method of analytical observation and to tackle this interpretative and emotional side of my research, I refer to Saikat Chakraborty's method on how to address the subjectivities contained in creative practices. As she mentions in her essay Using Narratives in Creativity Research: 'Carrying out narrative research requires researchers' reflexivity as it brings the personal dimension into the research.' (Chakraborty 2965). Similar to Blommaert, she acknowledges that the stories collected through narrative research can manifest themselves in many different forms and most importantly, are filled with subjectivities as they are rooted in each individual's personal experience (Chakraborty 2965). Chakraborty purports that it is the task of researchers to take these subjective elements contained in narratives into consideration and translate them into meanings with their own interpretations and hopefully, access a deeper understanding of creative practices (2966). As with Blommaert's concept of poetic structures Chakraborty recommends the use of Boje's antenarrative approach which consists of identifying 'non-linear, chaotic and random pieces of information contained 
in narratives. In the case of this research antenarratives represent fragments of stories, visual references or personal beliefs and values used by designers, which on the surface are not directly participating in the narrative of creation, but help to support, reinforce and inform its progression. These elements are essential to analyze in order to create a pattern of inconsistencies and organizational fragments and transpose them into meanings (Chakraborty 2967). Her method of analyzing patterns within assemblages of narrative fragments, combined with Blommaert's observation method help me not only in the interpretation of narratives but also to position myself as a researcher and justify my intentions regarding how I decide to organize and communicate my findings.

\section{Research methods}

This research examines the construction of narratives in fashion design, the ways in which narratives emerge through this practice and how they impact the process of creation and making of fashion artefacts. The creative project is constructed around a series of interviews with three fashion designers operating in various areas of the industry and whose work reflects the importance of narratives as essential tools in their practice. The first participant was Michael Zoffranieri, who has been working in the Toronto fashion industry for over seven years, and who is the creator behind the label ZOFF. The second interview was conducted with Stephanie Varey, a young designer who is currently enrolled in at the London College of Fashion's graduate program. The last interviewee was Maegan Mcwade, owner of her own alteration and repair shop specializing in custom designs. All participants have had significant experiences through

their careers that allow them to share and express this area of their work. In-person interviews were crucial to the work and their analysis was designed to offer an updated 
perspective on how narratives manifest themselves in the process of fashion design and how these narratives are later translated and communicated to the public. The research also examines how narratives can be used to generate meaning throughout the conception and production of garments and how these meanings can sensitize consumers to the stories behind the clothes that they wear.

Qualitative methods were followed, using semi-structured interviews to identify recurrent themes around the use of narratives in creative practices. Each interview has been conducted following a conversational approach in order to get in-depth insights into the participants' practices, philosophies and values in relation to design.

Instagram was used to search potential designers that would best fit the characteristics of this particular research and enrich the existent knowledge on narratives in fashion design. This platform and the visual nature of its function served as a way to identify local designers that already exhibited narrative qualities in their visual and textual posts. The first two interviews allowed for clear patterns around the implication and use of narrative to emerge. Those insights revealed a significant spectrum of findings in regards to the subject of my research. An additional interview was conducted afterwards to justify and confirm some of those patterns contained in the data retrieved from the conversations with the two first participants. Each participant was interviewed in their workplace in a natural and comfortable environment that they knew very well. This setting also allowed the participants to show some examples of their work to help answer to some questions during the interview.

The data collected through these interviews has been analyzed following Foucault's theoretical framework introduced in his essay What is an author. I use his concept of 'the work' to look at the relationship between designers, their creations and 
the context in which those were made. I then use Foucault's concept of discursive practices to interpret the different ways in which narratives are used and expressed by designers when reflecting on their practice. The creative component of this research, and the second part of the analysis was elaborated around Suzie R. Norris-Reeves approach to knowledge derived from fashion design practices. It explores the different ways in which these designers and myself as a researcher can convey meaning through the process of making as well as materializing and giving voice to the ways in which narratives manifest themselves during creation. The process of creation happened simultaneously with the collection of my data, editing each interview and visual footage while transcribing what had been discussed between myself and the designer. Using Suzie R. Norris-Reeves' concept of knowing through making, I elaborated my art piece as I was collecting every element that would contribute to its final form. After analyzing the interviews through a process of annotation and audio edits, similarities and differences in the discussions with the three designers were compiled. I then proceeded to make the documentary in a manner that was meant to convey the process of creation and the development of narrative while revealing thoughts about how designers made sense of how they view their practice and its meaning in the larger context of fashion. The visual direction the film and the incorporation of my interpretative artwork is intended to foster an understanding of the different forms and levels of narratives contained in creative process as well as how those manifests themselves through design. 


\section{Analysis}

Michel Foucault's theory of authorship and it's relation to this research

In the preliminary research on narrative studies, I found that Foucault's theory of authorship laid the foundation of how to approach and interpret my own work on the subject. It was the phenomenon of individualization of authors and the effect of this shift on how their work is perceived (Foucault 115) upon which the frame of this research was constructed. It was done so in a way that would bring more attention to the creative practices adopted by designers and what is derived from these practices, rather than limiting focus to the intentions of fashion designers as sole creators. Each of the designer participants were introduced to the objectives of this research and the differences between this approach and other research on design practices that follows a linear analysis of intentions through the creation of final artefacts. The eagerness of these participants to address the relevance of narratives in a way that emphasized nonlinearity and decentralized authorship reaffirmed the significance of the approach and the need to take a closer look at the elements that constitute narratives that are often overshadowed by an emphasis on idealized portrayals of fashion designers as creative geniuses. This facilitated a collaborative experience between myself and my participants, each interview bringing me closer to the understanding of the many ways through which creative work is initiated, evolves and brings to life meaningful fashion artefacts. By deconstructing the unity of a work through the analysis of key elements that formed it, my interviews not only allowed for deeper levels of understanding of creative practices, but also to establish recurrent themes which although expressed in different ways by my participants, led me to discover a pattern in relation to how narratives are used and expressed through fashion design practices (Foucault 115). Being able to establish this 
pattern helped frame and guide how the analysis and organization of the findings. It appeared that each interviewee, although taking part in different areas of fashion design, agreed on a common approach to the implication of narratives in their work. Narratives offered structural guidance allowing them to take part in larger conversations through the process of making.

\section{Application of the concept of Author-Function}

First introduced by Foucault, the concept of author-function is commonly used in this field of research to challenge the ideas of agency and authenticity which are both key concepts that can be applied more specifically to fashion design as a practice (124). If as mentioned by Foucault ideas are neither owned nor generated by designers, but are instead explored or challenged by the pursuit of the expression of their craft, then designers are involved in something much greater than the simple expression of their vision, materialized by what they create (Foucault 124). Foucault's author-function concept is abstract however it can provide a basis for understanding the concept of authorship in relation to disparate narrative elements and of fashion design as a discursive practice. One of the ways to apply this concept is to pay attention to subconcepts such as what Foucault calls discursive practices (131). Discursive practice can be defined as the different means by which designers use their voices through the practice of fashion design. Through conducting this research, I realized that each designer had their own interpretations of what it means for them to be a fashion designer, and through the analysis of their motives and beliefs I found multiple similarities relating to the perceived value of their work. Although they all had their own philosophies of work and their own personal values that inspired them to create, they 
each shared a commonality of their practice by initiating or participating in what they called a 'dialogue' through the act of design. The interview with Michael Zoffranieri offered clear insights as to what this concept meant in his practice:

I think it's two folds. I think I really love and respect and want to nurture those relationships of that dialogue of fashion and what it could mean for everybody involved, but at the same time, I'm also that creative spirit that want to get that story out there. It's always this balance of what do I want to say, what do I want to share with the world, but also what am I hearing, what am I involved in understanding my place and my position or my privilege and balancing what I want to do and what I want to make versus what the world is telling me to make and how I fit in those spaces.

This concept of dialogue will be used to express the different ways in which each designer is participating in the larger context of fashion narratives through the stories that emerge from their practices. For each there was an implication of 'something bigger' than just the act of making that led to all sorts of meaningful interpretation within their practices. One participant explained that without this dialogue, there is no reason or purpose to design, thus reaffirming a relationship to the construction of narratives. There are different ways in which the participants indicated that these dialogues make their practices more meaningful, such as increasing the level to which people can relate to the work, or to give them the means to react or comment on it. Taking part in a pre-established dialogue not only positions the work of designers in a larger context of application, but it also positions it in relation to other work participating in the same conversation thus motivating possibilities for continuity or 
progress and validating the interpretation of meaning. Stephany Varey explained the conversational aspect of design stating that

As a designer in this industry, I feel that you have a responsibility to share your perspective no matter what it is and sometimes I think it's hard. I think of what it is that I want to say and is it worth it that I'm saying it, is it gonna affect anything like is it gonna change anything? I think that the world in general can be a very depressing place and if my role with my designs is to create something big and grand and sculptural that might be a little bizarre looking I think that I'm doing my job to make people interested and influence them in a positive way.

The introduction dialogue offers a perspective through which the analysis of narratives can be made as it establishes the broad spectrum of application in regard to their construction and representation. It offers a context to the discovery of different layers of narratives and the many forms in which they can be expressed through the process of fashion design.

\section{Application of Foucault's concept of 'the work'}

In What is an Author, Foucault uses 'the work', to refer to the unity formed by all of the elements that generates it (115). In this research project, 'the work' refers to artifacts created by fashion designers as a central element around which all of the parts that were implicated in its making become relevant such as: the context in which creation takes place, its relation to previous or similar work, and the designer's intention. Emphasis is on the process behind the making of garments rather than the garments as they are in their final forms. The 'work' is examined using Bloomaert's ethnopoetic approach to identify patterns that link all of the different elements that 
form narratives without focusing solely on the meanings embedded in each of them. By applying these approaches, I was able to draw insightful comparisons between the narratives collected through the interviews. As Blommaert suggests, identifying these resemblances and recurring patterns in the way designers talked about their practices allows me to recognize recurring patterns in the way designers talked about their practices. (182).

\section{The cycle of design process}

What I discovered during discussions with the participants is that there was not a linear sequence of stages of progression in terms of the creative aspect of their work, rather, they referred an iterative series of steps, all taking part in a larger cycle. Although, according to the participants, the concept of dialogue, as identified by Zoffranieri and Varey is omnipresent at every stage of the design process, they all agreed that it was mostly used as an initiator for any form of creation as well as at the very end of the process to confirm the relevance of the final artifact. Dialogue is used naturally throughout the process of design to make sure that the creation of an artefact follows a certain line of thoughts and affirms the initial intentions and motives, no matter which design methods are employed and regardless of project specific variations. Then the act of creation follows several stages that occur in a relatively structured way including aesthetic and technical through evolution through iteration and progression toward the final form. Most participants agreed that it was hard for them to tell when the process was complete since many factors could influence the trajectory, offering unexpended results and opening avenues for new forms of dialogues. This dialogue, whether it is new or based on the original intention is used by the designers to make sense of their 
process, to add bursts of creativity and sometimes, to initiate making something else, thus starting a new cycle.

\section{How narratives fit in the cycle of design process}

By looking at where narratives fit into the cycle of creation, I discovered that they are used in different ways from one designer to another and that they can take many forms from personal stories to general systems of beliefs and are sometimes used to ensure the evolution of the creative process. Some examples of the purpose of narratives in their work derived from the designer interviews include:

- To spark imagination, generate inspiration/desire to create

- To build a cohesive story through the process of making

- To reaffirm or support design decisions

- To make sense of the progress/evolution of the design

- To communicate the intention and the story behind the process and later the artifact resulting from it

- To reinforce the significance and relevance of the final artifact

Although the examples above are not inclusive of all manifestations of narrative, the designers agreed that narratives were essential to design processes and that without their implications, there was no purpose to design.

Stephanie Varey on the importance of narratives:

People can look at your creations and interpret whatever they want from it and so you really have to justify everything, For me, it's like teaching. Choosing and creating a narrative that will teach people whatever it is you want to say or you 
want them to notice. I think it's really important because without a story, what are you doing, right? It's important because without that, there is no point to design.

This quote from the interview with Varey confirms how narratives are essential and inseparable elements of creative processes for her and indicates her belief in the overall importance to the field of design. It also indicates the relevance of using a narrative approach to assist others with understanding complexities of fashion design as a discursive and meaningful practice.

Within the documentary, my own interpretation of the narratives provide continuity within a nonlinear cycle of creation, to which designers can refer at any moment of the process. Narratives act as points of reference or guides throughout the creation and are naturally used by designers in every aspect of their work. One participant mentioned that she used narratives in their literary forms, to create a fictional story in which the main character (the wearer) would experience a series of different events while wearing her garment. This story allows her to imagine how this character, who is wearing the garment would feel or interact with its surroundings. Any event that might affect the creative process or influence design decisions are tested by integrating them into this narrative and by deciding whether they contribute to the story and help its progress or not. This example shows the structural aspect of narratives while reinforcing their referential status in fashion design processes.

The interviewed designers' narratives always seem to follow a progression since every step of the process has a possibility to add additional elements to the both the story that is told through the creation and the story that inspires and generates it. 


\section{Narrative Levels and Forms}

Discussions with the participants revealed that narratives are intertwined in many aspects of creative practices and manifest themselves in different forms. First, there are the narratives that frame the creation, influence and stimulate it. Those narratives are the easiest to depict as they are rooted in the creative process and frequently well understood and explained by designers (Norris-Reeves 51). They may vary in their representations, from sketches to poems to photographs or even samples of textiles or artistic references. Any elements that are used throughout the creation to contribute to its progress and development is part of this layer of narrative and is essential to fashion design. Secondly, there is the larger narrative in which design is taking place, which could be viewed as the context of creation. Although it was not always clear where the participant designers thought their designs fit into the larger context of fashion, they all agreed that they were influenced by what was happening around them at the time of the creation. Whether it is politics, environmental issues or aesthetics, each of them agreed that in order for their pieces to be relevant and impactful, they had to speak to certain elements to which people can relate. Although this narrative is part of the process of design, it did not seem to prevail as the primary narrative which had a much bigger impact on the evolution of the making of garments. Rather, it was explained by the designers as something they had to keep in mind in order to be able to sell their designs as in some cases this narrative was the element acting as a bridge between the abstract perception of fashion design and their customers. I sensed a feeling of detachment towards this layer of narrative throughout the interviews, as if the designers knew they had to consider it, but were not focused on it. 
Thirdly, there is the narrative used by designers to talk about their practices. This layer is represented by the way they choose to express and make sense of how they proceed to design, the methods that they use for that matter and in what ways these add value and meaning to their creations. It is the only narrative that is not directly linked to the creation as it contains the elements that define the designers' main philosophies behind creation and how they apply it to the making of garments. It is more detached in the sense that it does not contribute to the process; it manifests itself after its completion allowing the designer to look back on what has been created and to reflect on it (Norris-Reeves 51). I have encountered this layer of narrative through discussions with the participants while encouraging them to share what it meant for them to create. This layer is far more explanatory and analytic in its nature as it reveals more general facts around creation, design and fashion. For this reason, this layer is the most accessible narrative since it derives from the conversations around design processes and allows others to understand how they unfold.

The last layer of narrative as described by Saikat Chakraborty in her essay Using Narrative in Creativity Research is my own interpretation as a researcher, which is built from applying reflexivity in the analysis of stories collected through research (2965). This additional layer of narrative contains all of my interpretations and understanding of the stories I have encountered and collected throughout the process of interviews and how I choose to present and share it through my writing. Not only is this layer is essential in order to make sense of the data that I have collected, but it also adds a more personal dimension to this research as it allows for me to interpret and analyze all of the subjectivities and to extract meanings from them (Chakraborty 2966). 
Applying Michel Foucault's concept of discursive practices to my creative work.

The creative portion of this research allows me to make sense of all of the elements of narratives collected and to express and represent them in a cohesive and exploratory piece. Through this process, I have applied Michel Foucault's approach of discursive practices in order to validate the methods I have chosen to express my data, and to justify the final result and its benefits and contributions to the research as a whole.

Foucault points out that authors should not be seen as owners of ideas, rather as actors in their perpetuation and their diffusion (131). While adopting this state of mind, I have organized and, through the making of an artwork, given voice to all of the stories collected through my interviews with the intention of putting them together in a way that helps to keep the dialogue in which they are rooted alive. This dialogue is expressed through a documentary film, which follows the progression of my work inspired by the narratives of the designers I have interviewed. The documentary will allow showing the full process and the evolution of this research on narratives as well as offer an interpretation of the subjective nature of this research. According to Saikat Chakraborty this will allow more meaning to be conveyed through the expression of my findings as the method pushes different ways of exploring, interpreting and representing the data (Chakraborty 2965).

The creative components

\section{The art piece}

The art piece explores dialogue as an essential concept in creative process by regrouping different forms and layers of narratives, from inspiration to quotes from the 
participant designers as well as creative intentions such as philosophy and values of practice. These have been represented using multiple mediums to express the different levels of creative processes in which they are rooted. The main focus of the art piece is a series of envelopes of different types, containing elements of narratives, stories and images expressed by the designers. As explained previously when introducing Boje's concept of anternarrative, making this art piece helped to gather fragments of stories as well as other visual elements inspired by the designers' narratives which would have otherwise been discarded and to consider them as actors in the larger conversation of creative practices that this research is trying to uncover. These envelopes, which are different sizes and origins, are arranged on the art piece in a chaotic way to express the nonlinearity of creative processes (see figure 1). To create an element of tension which in this research represents the roles of narratives as structural and referential, each envelope has been stitched on the art piece using a continuous thread (see figure 2).

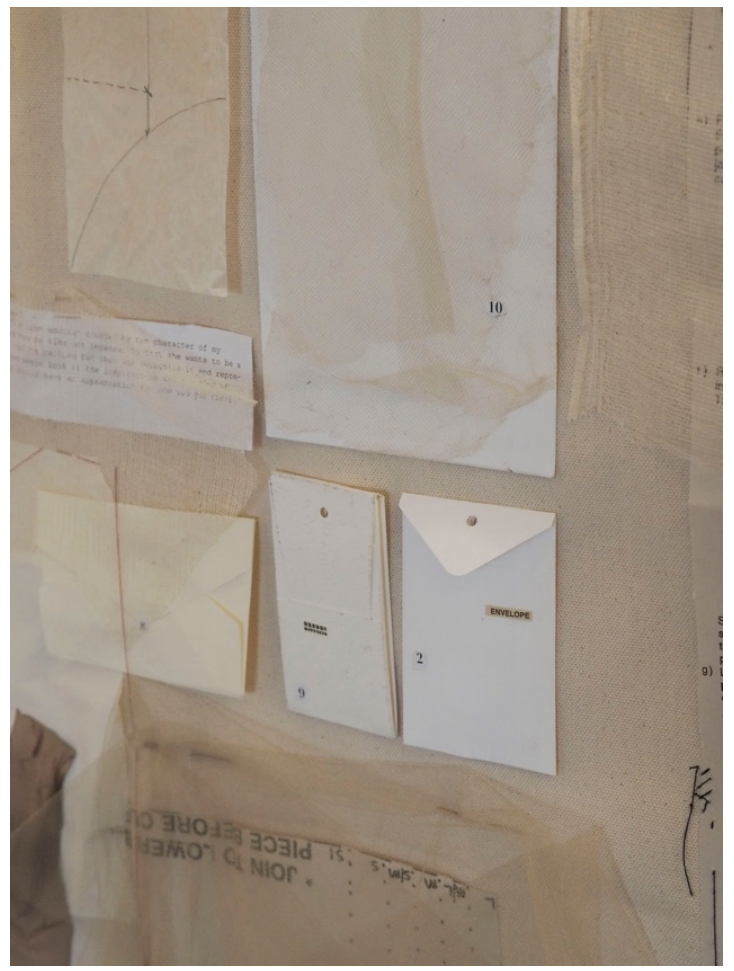

Figure 1. The envelopes

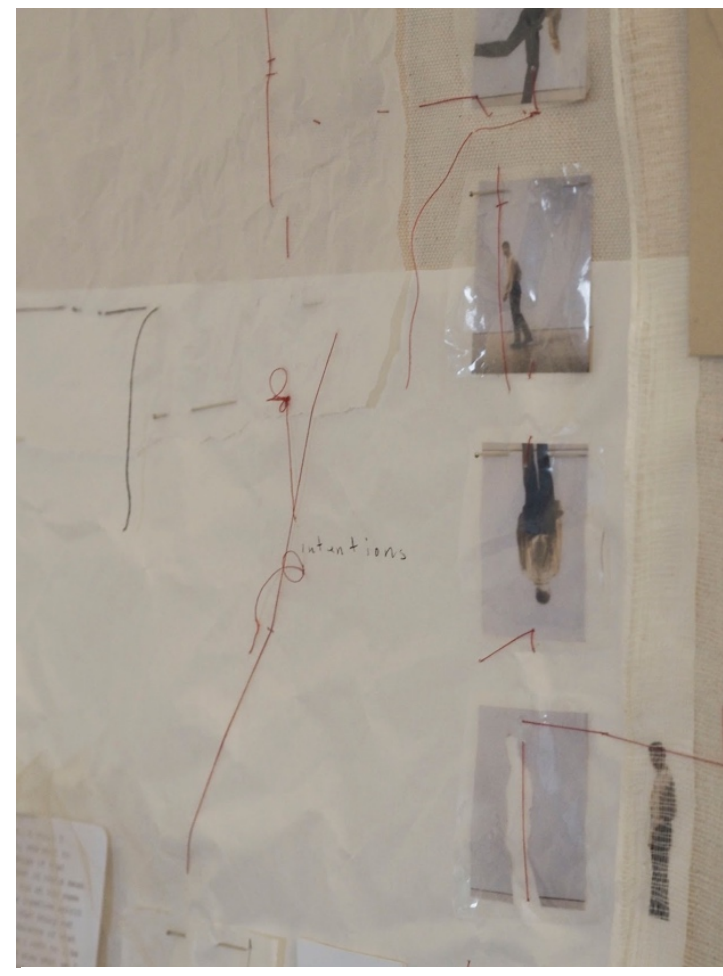

Figure 2. The thread 
This continuity expresses the idea of progress associated with narratives and the way through which they organize all of the elements of the making of garments and guide their creation. The addition of the continuous thread allowed to connect the disparate elements contained in the interviews choosing different pathways each time and building a rich experience of the narrative rather than a linear story.

This art piece showing its progress and creation, offer a visual interpretation of the abstractness of storytelling with the intent of making this research more accessible. The components of the artwork represent all of the different elements that gathered from conversations with three designers, presented in a visual ensemble that appears chaotic while showing the reality of creative processes (see figure 3).

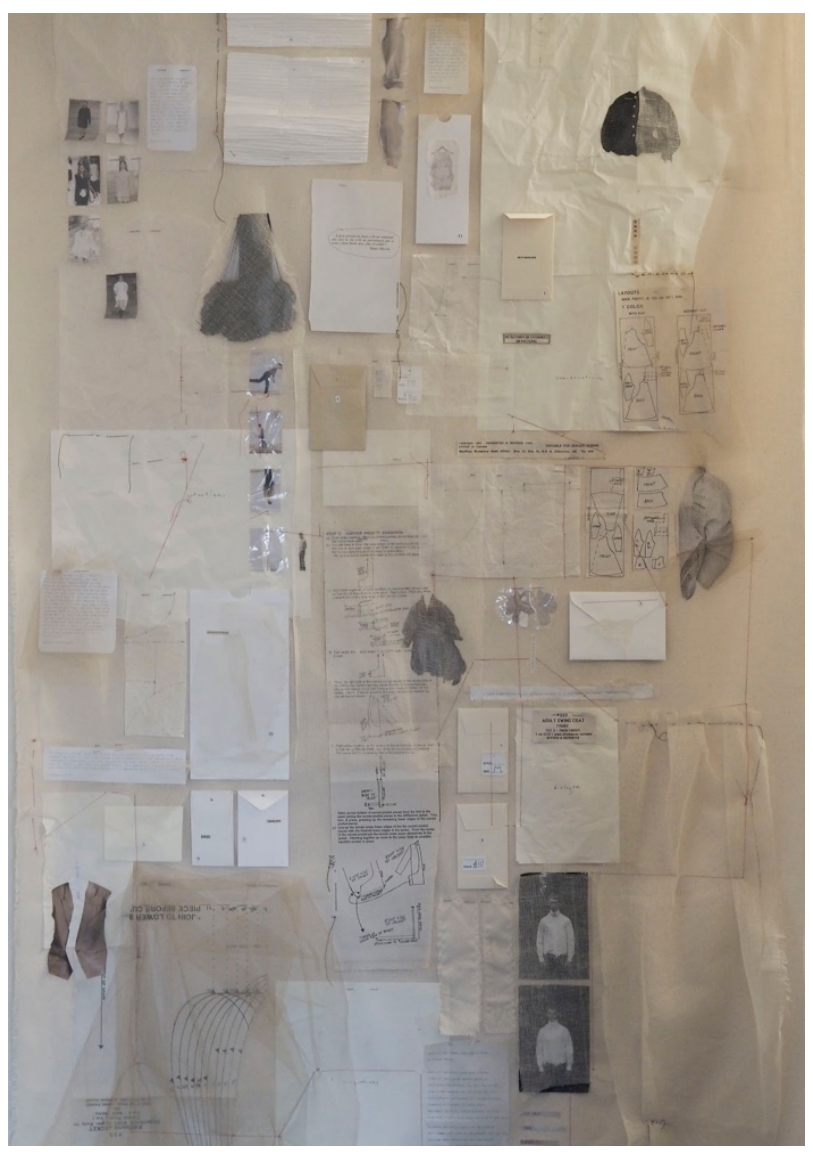

Figure 3. The ensemble 


\section{The documentary}

The creation of a documentary allowed myself as a researcher to take part in the conversation about narratives and to share my interpretation. (Chakraborty 2965). Adding this element to the creative portion of this research will help to raise questions, inspire or sparks interest for the audience about what goes on behind fashion design.

\section{The voices}

The different voices articulated in the documentary refer to the levels of narratives discussed in the previous analysis. First there is the voice of each of the designers, which express the layer of narrative that they used to tell their story and share their views on how they implement narratives through creation. Then there is my own voice which is used to create the transitions between each interview segment and ensure a fluid and gradual message. The integration of a personal interpretative voice helped to structure the documentary in a way that would convey the conclusion of this research. Its continuous progression and the open-ended note of the ensemble express the preliminary level of this research and the depth of its findings. All together the different voices are joined in a common narrative that relates to the concept of dialogue previously expressed and analyzed. It is intended to reflect how the designers, despite each having their own ways of using narratives to create, commonly acknowledge this larger context of creation which goes beyond their practice.

\section{The visual}

The decision to represent the visual components in black and white was made in order for the audience to pay more attention to the story told through the documentary. 
The muted visual choices allowed me to bring uniformity to the piece and to combine the multiple stories in one coherent message. The documentary showcases a series of clips of the designers' progress work such as inspirations, sketches and patterns. Those images prioritizing clips showing the hands of each designer working support the initial intention of this research of paying attention to the stories behind garments rather than perpetuating the idea of portraying designers as initiators. In addition to the clips featuring the designers' portions showing the process of me making the art piece were integrated. These were added with the intention of showing how all of the data obtained through this research was collected, how it had been analyzed and then materialized into a visual artefact. This integration also helps support the final message of the documentary which resulted from the interpretations of the outcomes of this research.

\section{The message}

The documentary follows a slow progression uncovering one by one the designers' narratives combined with the interlaced images of creations. The overall story follows a steady evolution in reflection to the nature of this research and the long conversations held with Michael, Stephanie and Maegan. All of the segments of stories shared by those designers have been selected in order to express the outcomes of this research and hopefully to raise additional questions for future research. The overall goal of this piece is to share a glimpse of how narratives are used by fashion designers, how they influence their work and ultimately sensitize the audience to pay more attention to the stories behind fashion artefacts. 


\section{Creative practices as a source for the production of knowledge}

Through her research on narratives in fashion design, Suzie R. Norris-Reeves argued that by documenting and making sense of creative practices leading to the production of fashion artifact, it is possible to consider stages of the process as sources of production of knowledge (112). She defends that artifacts produced by fashion designers can convey meaning beyond the ways in which they are seen and interpreted in their final form if the process leading to their conception is well documented and expressed by designers (146). Throughout her research she talks about the concept of 'knowing knowledge' which she explains as knowledge that is never said or never put into words because it exists as all of the competencies acquired by designers that are essential to their practice, but not necessarily made explicit (Norris-Reeves 107). It became apparent as I was conducting the interviews for this research that, other than through interviews or conversation with peers, information about narratives and design practices as described by Norris-Reeves, was not something designers were accustomed to sharing. In fact, narratives that are the foundation of creative practices remain highly sensitive subjects for designers to share, as talking about them tends to expose a part of themselves that may be rooted in deeply personal beliefs and values. Norris-Reeves states that the reasons and motives behind creation as well as the narratives that guides its process, even if they are essential to fashion designers, often remain private even sometimes after the creation is done and shared with the public (Norris-Reeves 108). With this research, my intentions were to reveal this portion of their work, in order to understand some of the levels of meaning that cannot be accessed solely when looking at their work. Through my analysis I wish to offer a different point on view on how design 
practices and artifacts produced by fashion designers can be considered as meaningful sources of knowledge.

When I started the interview process for this research I did not have expectations regarding the information I was going to be able to access, or even how many designers I would to have to interview in order to get a sufficient insight into this part of their work. What I was surprised to discover after completing my third interview is that there were a lot of similarities and points of comparison between the designers' way of using narratives and how those impacted their practices. Those similarities, such as the concepts of dialogue, non-linearity and the idea of progress associated with using narratives, although expressed differently by each designer are in my opinion, some of the elements that validate design as production of knowledge. Without knowing it, the designers all drew the same conclusions relating to how and why they create and even if they were all acting in different areas of fashion, the three of them shared the same basic beliefs in regards to how design should happen in today's context production.

By paying attention to the motives and intentions behind fashion design it is possible to reach a better understanding of this practice and to validate its meaning. Fashion design as a practice demands a certain level of implication of the self in order to enter the more vulnerable creative mind space which is also happening in very different ways from one designer to another and is hard to categorize or break down into clear stages. By entering in a creative process, myself and through the making of the creative part of this research, I wish to express what Suzie R. Norris-Reeves defines as 'the unspoken' and give voice to the thoughts and process that goes behind the clothes that are produced by fashion designers (108). By making the art piece, I wish to gather and express all the similarities contained in my conversations with designers which will then 
be progressively put together in the documentary into a common and shared story taking part into the same dialogue of creation.

\section{Conclusion}

This research allowed me to gain more insights into the practice of fashion design, more specifically in regard to the role of narratives within creation. Focusing on this particular aspect of design and working directly with practitioners in the field of fashion allowed the formulation of new answers to questions about the role played by narratives and most importantly to identify them as structural and referential tools. The initial assumption, associating narratives as generators of meanings was challenged by the concept of dialogue evoked by the participants. This concept positioned itself as a central element for the analysis, demonstrating that for fashion designers, a meaningful practice could only be achieved by acknowledging the participation to existing dialogue as the core element of their work. The framework established by Suzie R. Norris-Reeves as well as Foucault's theory of authorship supports the creative portion of this research which helped to express the data and findings in a different and hopefully more accessible way.

Although this constitutes preliminary research on the subject of narratives and that there are a lot of questions are still yet to be answered, its outcomes demonstrate that narrative analysis can go beyond the subjectivities associated with this area of design and allow for patterns to emerge among fashion design practices. Further research on the concept of dialogue in creative practices could benefit the existing theory on narratives in fashion design especially in regard to the influence of the context in which designers create. The limited timeframe of this research did not allow 
comparison with those exterior dialogues to determine if there was similarities or patterns that could be identified in this regard. Further research could also include a wider range of actors in the fashion context, such as the consumer, which could help identify how narratives are translated through the making of garments after the process of creation is completed.

The main elements confirmed by this research are that the most meaningful conversations are initiated and rooted in storytelling and that more insights and conclusions can be drawn from the narratives shared by practitioners than by the outcomes of their creativity that are fashion artefacts. 


\section{Works cited}

Blommaert, Jan. "Applied Ethnopoetics." Narrative Inquiry, vol. 16, no. 1, 2006, pp. 181-190.

Bruner, Jerome S. Acts of Meaning. Harvard University Press, 1990.

Burnette, C., "A Theory of Design Thinking", Torquay Conference on Design Thinking, Melbourne: Swinburne University of Technology, 1st November 2009.

Chakraborty, Saikat. "Using Narratives in Creativity Research: Handling the Subjective Nature of Creative Process." The Qualitative Report, vol. 22, no. 11, 2017, pp. 2959-2973.

Currie, Mark. Postmodern Narrative Theory. Palgrave Macmillan, 2011.

Foucault, M., "What is an Author?" in Language, Counter-Memory, Practice: Selected Essays and Interviews, eds. D. Bouchard F., D. Trans. Bouchard F. \& S. Simon, New York: Cornell University Press, Ithaca, 1977, pp. 113-127.

Friedman, K., "Theory construction in design research: criteria: approaches, and methods", Design Studies, vol. 24, no. 6, 2003, pp. 507-522.

Norris-Reeves, Suzie, "Constructing a Narrative of Fashion Practice as Inquiry.", Royal College of Art. 2014 pp. 63-132.

Kleres, Jochen. "Emotions and Narrative Analysis: A Methodological Approach." Journal for the Theory of Social Behaviour, vol. 41, no. 2, 2011, pp. 182-202. 